\title{
Shields against ultraviolet radiation: an additional protective role for the egg capsules of benthic marine gastropods
}

\author{
Timothy A. Rawlings* \\ Department of Biological Sciences, University of Alberta, Edmonton, Alberta, T6G 2E9 and \\ Bamfield Marine Station, Bamfield, British Columbia, V0R 1 B0 Canada
}

\begin{abstract}
While structurally complex benthic egg capsules can lower the vulnerability of gastropod embryos to a variety of environmental risks, including predation, desiccation, osmotic shock, and bacterial attack, little is known about their ability to shield embryos from ultraviolet radiation (UV). I examined the exposure of benthic egg capsules of the marine intertidal gastropod Nucella emarginata to solar radiation under natural field conditions, and assessed the degree to which capsule walls protect embryos from UV. Although capsules were laid under dense algal canopies at some intertidal sites, at more wave-exposed locales they were deposited in areas directly exposed to solar radiation. Measurement of UV transmittance through the inner and outer wall of these capsules indicated that $<5 \%$ of incident $300 \mathrm{~nm}$ UV-B and $<55 \%$ of incident $360 \mathrm{~nm}$ UV-A radiation entered the capsule chamber. The outer capsule wall was responsible for the majority of UV absorption. Outdoor experiments confirmed that embryos unprotected by the thick outer capsule wall suffered higher mortality than embryos within whole capsules, when exposed to natural solar radiation. The spectral properties of capsule walls differed significantly among populations of $N$. emarginata, and among capsules laid by different species of Nucella. This variation was associated with intra- and interspecific differences in the thickness of the outer wall. There was no polarity to the UV-absorbing properties of the outer wall of $N$. emarginata capsules, however, and no evidence of methanol-soluble UV-absorbing compounds. Although the mechanism of UV absorption remains unclear, $N$. emarginata capsule walls do provide embryos with substantial protection from UV. These findings thus demonstrate an additional protective role for the capsules of benthic marine gastropods.
\end{abstract}

KEY WORDS: Egg capsules - Gastropoda - Nucella emarginata $\cdot$ Reproduction UV

\section{INTRODUCTION}

With the recent discovery of an upward trend in the amount of solar ultraviolet radiation (UV) reaching the earth's surface (e.g. Smith et al. 1992, Kerr \& McElroy 1993) and the realization that UV can penetrate deeper into the water column than previously believed (Smith et al. 1992, Herndl et al. 1993), there has been a growing interest in the impact of natural levels of UV-B (280 to $320 \mathrm{~nm}$ ) and UV-A (320 to $400 \mathrm{~nm}$ ) on marine organisms. These studies have focused on (1) the negative efferts of IVV on various natural popu-

•E-mail: trawling@gpu.srv.ualberta.ca lations of marine organisms (e.g. Damkaer \& Dey 1983), (2) the mechanisms by which organisms protect themselves from short wavelength radiation (e.g. Dunlap et al. 1986, Karentz et al. 1991, Shick et al. 1992, Stochaj et al. 1994), and (3) the impact of increased levels of UV on intertidal and shallow subtidal community dynamics (e.g. Jokiel 1980, Smith et al. 1992, Herndl et al. 1993)

While considerable attention has been directed towards the effects of UV on adult stages of benthic marine invertebrates, substantially less is known about the susceptibility of their embryos and larvae to UV Alternate stages in the life-histories of many marine organisms experience extremely different light regimes (see Thorson 1964). For example, $\sim 70 \%$ of benthic 
marine species produce free-swimming planktotrophic larvae (Thorson 1950). With limited powers of locomotion, these larvae may be exposed to considerably higher doses of UV during development than benthic adults confined to shaded or deeper water habitats. Direct exposure of embryos and larvae to artificial UV sources has resulted in such stage-specific effects as abnormally delayed cleavage (Ciese 1938 as cited in Worrest 1982), photokinetic responses (Pennington \& Emlet 1986; and references therein), or death (Damkaer \& Dey 1982, 1983, Prnnington \& Emlet 1986). The large buoyant eggs and later developmental stages of some species may be partially protected from the mutagenic effects of UV by strong pigmentation (Pennington \& Emlet 1986, Griffiths 1965 and Ryberg 1980 as cited in Pennington \& Emlet 1986) or through biochemical protection associated with the presence of mycosporine-like amino acids (MAAs; Karentr. 1994). Likewise, larvae may survive periods of intense UV irradiance by diel migrations into deeper water (Pennington \& Emlet 1986). Further research is necessary, however, to determine how well established such mechanisms of UV protection and avoidance are among the embryos and larvae of benthic marine invertebrates.

Many benthic marine invertebrates shield their embryos from direct exposure to environmental risks by packaging them within protective coverings. [As defined by Giese \& Pearse (1974), all pre-metamorphic developmental stages will be termed 'embryos' during their confinement within these protective coverings]. This is a common phenomenon among members of such invertebrate phyla as the Platyhelminthes, Nemertinea, Annelida, and Mollusca. These species deposit their eggs within a variety of structures, ranging from tough multi-laminated capsules to soft gelatinous ribbons and masses. While these protective coverings may lower the vulnerability of embryos to predators (e.g. Spight 1977, Brenchley 1982, Rawlings 1990, 1994), desiccation (Fretter \& Graham 1962, Pechenik 1978, Rawlings 1995a), osmotic stress (Pechenik 1982 1983), and attack by bacteria and protists (Lord 1986, Rawlings 1995b), little is known about the ability of capsule walls and egg mass jelly to shield embryos from UV (but see Biermann et al. 1992).

In this study I examined the spectral properties of egg capsules produced by the temperate marine gastropod Nucella emarginata (northern species; Palmer et al. 1990). These snails are common inhabitants of the rocky intertidal zone from Alaska to California and range across wide extremes in wave-exposure. Females deposit eggs year-round within 6 to $10 \mathrm{~mm}$ long vase-shaped egg capsules and attach these to firm substrata in the intertidal zone. Embryos develop within the capsule chamber for as long as $140 \mathrm{~d}$ (see
Palmer 1994) before hatching as juvenile snails (Strathmann 1987). During this developmental period, the capsule wall, consisting of both a thin inner wall $(<5 \mu \mathrm{m})$ and thick outer wall (usually $<100 \mu \mathrm{m}$; Rawlings 1990,1995b), represents the primary barrier separating embryos from sources of mortality associated with their external environment. The objectives of this study were (1) to estimate the degree of exposure of naturally deposited capsules to solar radiation, (2) to measure the transmittance of UV across the walls of these capsules, and (3) to determine the vulnerability of encapsulated embryos to UV

\section{MATERIALS AND METHODS}

Survey of naturally deposited egg capsules of Nucella emarginata. In August 1994, I conducted a field survey to document the range of intertidal microhabitats used as spawning sites by Nucella emarginata, and to assess the exposure of egg capsules to direct solar radiation within these microhabitats. This fieldwork was conducted in the vicinity of the Bamfield Marine Station (BMS) on the west coast of Vancouver Island, Barkley Sound, British Columbia, Canada $\left(48^{\circ} 50^{\prime} \mathrm{N}, 125^{\circ} 08^{\prime} \mathrm{W}\right)$. I chose 3 intertidal sites for this survey based on their exposure to wave action and also on the local availability of intact capsules at these sites during the survey period. These sites were (1) Ross Islet $\left(48^{\circ} 52^{\prime} 12^{\prime \prime} \mathrm{N}, 125^{\circ} 9^{\prime} 42^{\prime \prime} \mathrm{W}\right)$, (2) Wizard Islet $\left(48^{\circ} 51^{\prime} 24^{\prime \prime} \mathrm{N}, 125^{\circ} 09^{\prime} 36^{\prime \prime} \mathrm{W}\right.$ ), and (3) Kirby Point $\left(48^{\circ} 50^{\prime} 42^{\prime \prime} \mathrm{N}, 125^{\circ} 12^{\prime} 24^{\prime \prime} \mathrm{W}\right)$. These have been ranked in wave-exposure based on (1.) the maximum height of the Balanus glandula zone, (2) the lowest height of vascular plants, and (3) offshore measures of wave height; all 3 measures have placed these sites in the following order along a gradient of increasing waveexposure: Ross Islet < Wizard Islet < Kirby Point (A. R. Palmer unpubl. data).

At each site, a $10 \mathrm{~m}$ stretch of shoreline was selected in a region where Nucella emarginata and their egg capsules were abundant. A 5 to $10 \mathrm{~m}$ long transect line was then placed parallel to the waterline, at a tidal height that intersected the vertical distribution of $N$. emarginata (Ross Islet: $2.43 \mathrm{~m}$ (above Extreme Low Water Spring, ELWS, chart datum); Wizard Islet: $2.91 \mathrm{~m}$; Kirby Point: $3.20 \mathrm{~m}]$. To determine the availability of microhabitats for capsule deposition within the selected area, I placed a $0.1 \times 0.1 \mathrm{~m}$ quadrat (divided into $25 \times 0.004 \mathrm{~m}^{2}$ grids) at intervals of either 0.25 or $0.5 \mathrm{~m}$ along the transect line. Within each quadrat, I estimated the percent cover of any algal canopy (e.g. Fucus gardneri, Mastocarpus papillatus) covering the primary substratum. This algal cover was then removed and the percentage cover of all understorey microhabitats estimated. 
To determine the microhabitats used for capsule deposition by Nucella emarginata, I searched for 20 groups of intact capsules within $0.25 \mathrm{~m}$ of the transect line. A group of capsules consisted of either a single clutch of capsules laid by 1 female, or an aggregation of multiple clutches produced by many females. Once a group of capsules was found, it was marked by attaching a piece of flagging tape next to the capsule mass. Because any algae overlying these capsules had to be displaced to locate each group, I could not estimate the exposure of capsules to direct solar radiation on the same day that they were tagged. Upon returning to these sites, usually on the following day, I noted whether capsules were visible prior to displacing the algal canopy. If capsules were visible, I measured the vertical and horizontal angle of unobstructed exposure to sunlight using a modified map divider and protractor (see Fig. 1), and also the mean direction of exposure using a compass. The quadrat was then centered over the group of capsules, and the percentage cover of algal canopy and understorey microhabitats estimated, as described above. Because $N$. emarginata capsules are firmly fixed to the substratum and rarely removed by predators or wave action, the selection of specific

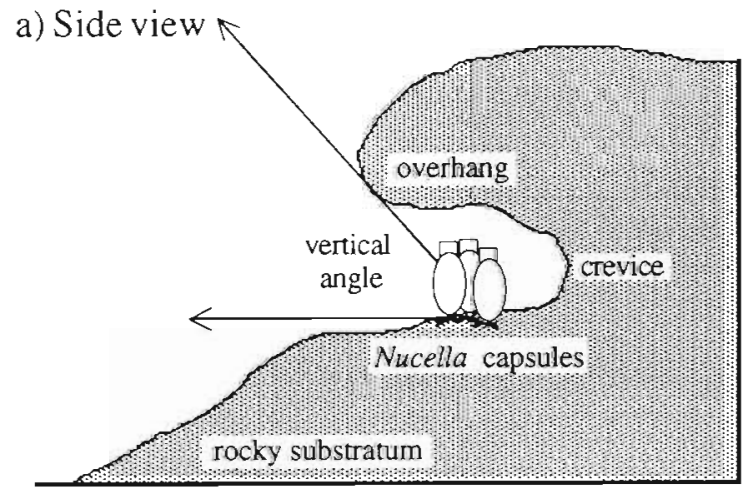

b) Top view

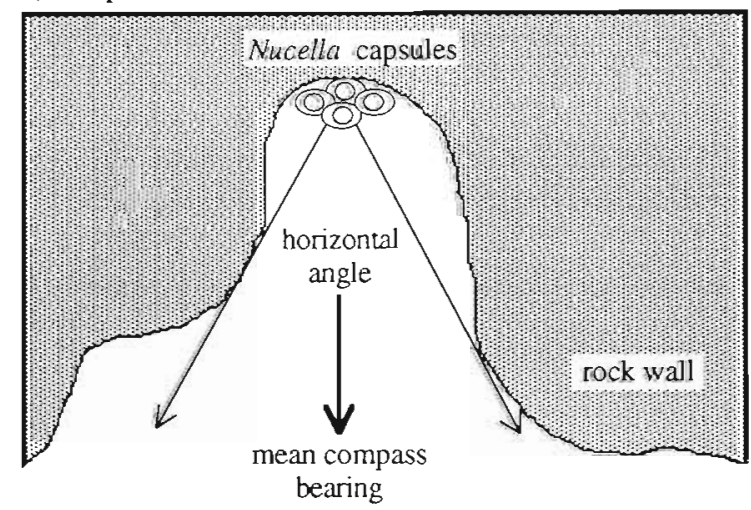

Fig. 1. Nucella emarginata. Measurement of (a) vertical and (b) horizontal angles of exposure of 2 naturally deposited groups of egg capsules to solar radiation. Angles were measured using a map divider and modified protractor microhabitats for spawning was assumed to reflect a direct preference for these microhabitats rather than a differential 'loss' of capsules among microhabitats.

The types of substrata on which capsules were deposited were also recorded for each group of capsules. Because capsules were laid almost exclusively on bare rock and the shells of the barnacle Semibalanus cariosus, I categorized capsules according to whether they were deposited (1) on bare rock, nestled against other organisms, (2) inside $S$. cariosus tests, (3) on the outside surfaces of $S$. cariosus tests, or (4) on open bare rock. This classification provided a crude index of the relative exposure of capsules to desiccation and solar radiation $(1=$ most protected, $4=$ most exposed); this ranking did not consider the potential ameliorating effects of an overlying algal canopy, if present. This procedure was repeated for all 3 study sites.

In early September 1994, I examined a fourth intertidal site located inside the entrance to Execution Cave, Barkley Sound $\left(48^{\circ} 48^{\prime} 48^{\prime \prime} \mathrm{N}, 125^{\circ} 10^{\prime} 36^{\prime \prime} \mathrm{W}\right)$. This site was of interest because of the unusual conditions associated with the cave environment (high humidity, low solar radiation) and the marked difference between microhabitats selected for capsule deposition at this site compared to the other locales. I quantified this difference by placing $0.1 \times 0.1 \mathrm{~m}$ quadrats over the first 20 groups of capsules found within the cave, and recording the percent cover of microhabitats around each group of capsules and the substrata on which the capsules were deposited.

Spectral properties of Nucella egg capsules. The spectral properties of $N$. emarginata egg capsules were measured using a fiber optic probe system originally designed to examine light absorption through thin layers of plant tissue (see Vogelmann \& Björn 1984, Vogelmann et al. 1988, 1991). To examine light transmittance through $N$. emarginata capsule walls, capsules were opened, emptied of contents, and rinsed with distilled water. A small piece of the capsule wall $(-1.5 \times 1.5 \mathrm{~mm})$ was then cut from the central region of the capsule case and mounted between 2 plastic coverslips. Each coverslip had a $1 \mathrm{~mm}$ diameter hole drilled at identical positions, such that when these 2 holes were superimposed light could travel across the exposed capsule wall unimpeded by the coverslips. A piece of wet absorbent tissue was also compressed between the coverslips to ensure that the capsule piece remained moist. Once the capsule was secure, the coverslips were mounted in a permanent holder positioned a fixed distance $(180 \mathrm{~mm})$ from a light source. Collimated light, provided by a $150 \mathrm{~W}$ xenon arc lamp, was focused on the outer surface of the capsule piece. The light gathering end of a modified fiber optic probe (16 $\mu \mathrm{m}$ in diameter), mounted in the eye of a needle 
and attached to a micromanipulator, was then brought to within $0.06 \mathrm{~mm}$ of the inside layer of the capsule wall. The opposite end of the fiber optic probe was connected to a spectroradiometer interfaced with an IBM computer.

I recorded the intensity of radiant energy crossing the capsule piece at $2 \mu \mathrm{m}$ intervals for a range of wavelengths spanning both the UV-A $(320$ to $380 \mathrm{~nm}$, including 1 measurement at $400 \mathrm{~nm}$ ) and the UV-B region (280 to $380 \mathrm{~nm}$ ). Each experimental trial was replicated 3 times using the same capsule piece. For each 'within capsule' replicate, the fiber optic probe was kept at the same distance from the light source, but was moved to a new position $\sim 0.2 \mathrm{~mm}$ on either side of the original measurement. Each experimental trial was calibrated against a control trial (3 replicates) in which the fiber optic probe was positioned at the same distance from the xenon light source, with coverslups and stand in place, but without a capsule piece present. Experimental trials and their respective control trials were always run consecutively to minimize any error associated with a temporal change in the output from the xenon light source. Percent transmittance values for capsule pieces were calculated by dividing the light transmittance for experimental trials by the average transmittance for each control trial. A correction was applied to all measurements of light transmittance to negate the effect of light scattering by capsule walls (see Day et al. 1992). To do this, recordings of light transmittance were made at $500 \mathrm{~nm}$ for a representative group of all capsules used in this study. Based on the color of these capsules, relatively little light should be absorbed by the capsule wall at this wavelength; hence, any reduction in light intensity due to the capsule piece must result from light scattering. All transmittance values in the UV-A and UV-B range were corrected by dividing by the percentage of light transmitted across the capsule wall at $500 \mathrm{~nm}$.

Light transmittance was also measured at various depths within the thick outer capsule wall. The fiber optic probe was advanced until it just contacted the inner surface of the capsule piece and was then driven through the capsule wall by a stepping motor $(0.5$ to $1.0 \mu \mathrm{m}$ steps). A Gaertner microscope was used to guide the orientation and position of the probe. Light readings were recorded at $2 \mu \mathrm{m}$ intervals through the capsule wall for a representative wavelength of $300 \mathrm{~nm}$. The percentage of light transmitted was determined by dividing the amount of light detected at specific depths in the wall by the amount of light detected once the probe had completely penetrated the capsule piece. A correction due to scattering was applied by fitting a curve to the measurements of light transmittance with depth of penetration (in percent) for scans at $300 \mathrm{~nm}$ and $500 \mathrm{~nm}$ for the same capsule pieces. Once these functions had been determined, transmittance values at $300 \mathrm{~nm}$ were divided by the percentage of light transmitted at $500 \mathrm{~nm}$ for specific depths

Using these techniques, in May 1994 I compared the spectral properties of freshly spawned capsules from 3 populations of Nucella emarginata in Barkley Sound: Grappler Inlet ( $48^{\circ} 49^{\prime} 54^{\prime \prime} \mathrm{N}, 125^{\circ} 06^{\prime} 54^{\prime \prime} \mathrm{W}$ ), Ross Islet, and Kirby Point. Capsules were also collected from a laboratory population of $N$. emarginata, consisting of snails born and raised entirely at BMS. Initial tests examined the spectral properties of the inner and outer capsule wall separately. All subsequent examinations used the whole capsule wall, except where noted otherwise

I tested for the presence of UV-absorbing MAAs within Nucella emarginata capsule walls by comparing the spectral properties of paired capsule pieces soaked in seawater versus those soaked in $80 \%$ methanol, a solvent employed to extract MAAs (Karentz et al 1991). Five laboratory-spawned capsules were bisected and rinsed in sterile seawater to remove their contents. One half of each case was then placed in $5 \mathrm{ml}$ of sterile seawater, while the matching piece was deposited in $5 \mathrm{ml}$ of $80 \%$ methanol. All capsules pieces were kept in these solutions for $24 \mathrm{~h}$ at $4^{\circ} \mathrm{C}$; MAAs are readily extracted by methanol over the course of only a few hours (e.g. Karentz et al. 1991). Following this, I soaked all capsule pieces in sterile seawater for $2 \mathrm{~h}$ and compared the spectral properties of matching capsule halves.

To compare the spectral properties of capsules among species, in May 1994 I collected capsules from 2 other species of Nucella, $N$. lamellosa and $N$. canaliculata, at intertidal locations in Grappler Inlet and Kirby Point, respectively. The spectral properties of these capsules were measured as described above for $N$. emarginata capsules.

Vulnerability of encapsulated embryos to ultraviolet radiation. Between July and September 1993, I conducted 2 sequential outdoor experiments at BMS to compare the vulnerability of embryos within stripped and whole capsules to UV Both experiments followed the same protocol. For Expt I, pairs of capsules were collected from clutches laid by laboratory-raised female Nucella emarginata. One capsule from each pair was stripped of 2 panels of its outer capsule wall (Rawlings 1995b), and the other was left whole. All capsules contained late 3rd-stage or early 4th-stage veligers, (LeBoeuf 1971). Paired capsules were arranged side by side on each ray of a 6 -rayed Tygon ${ }^{\text {TM }}$ holder (see Rawlings 1995b). Once 12 holders had been filled with capsules, each holder was placed in a sterilized culture jar containing $250 \mathrm{ml}$ of autoclaved, antibiotic-treated $10.050 \mathrm{~g} \mathrm{l}^{-1}$ penicillin; $0.030 \mathrm{~g} \mathrm{l}^{-1}$ 
streptomycin) seawater, such that capsules were suspended approximately $20 \mathrm{~mm}$ below the water surface. Each jar was then randomly assigned to 1 of 3 sunlight treatments ( $n=4$ jars treatment ${ }^{-1}$ ): (1) dark, (2) sunlight filtered to remove UV-A and UV-B (UV-filtered), and (3) sunlight filtered to remove wavelengths shorter than UV-A and UV-B (UV-exposed). Treatment conditions were created by mounting either an opaque Plexiglas cover, a UV-filtering Acrylite cover $150 \%$ cutoff at $\sim 395 \mathrm{~nm}$ ) or a UV-transmitting cover $(50 \%$ cutoff at $\sim 285 \mathrm{~nm}$ ) above each culture jar. The spectral properties of each Acrylite plate were confirmed using a UV visible Perkin-Elmer Spectrophotometer (Coleman 139).

Each culture jar was inserted into a rack mounted in an outdoor seawater tank. The rack consisted of a wooden frame with 4 removable opaque plastic trays; each tray had 3 wells in which a culture jar could be positioned. Treatment conditions were arranged in a randomized block design, such that 1 jar from each treatment was placed in the same tray. Because the jars sat snugly within their wells, the only light to enter each jar had to pass through the Acrylite or Plexiglas cover mounted above. Underneath the rack, each jar was bathed in a pool of flowing seawater, thus keeping the water temperature within each jar relatively stable during the experiment $\left(11\right.$ to $13^{\circ} \mathrm{C}$ ). Temperature readings were taken within each jar at irregular intervals. On sunny days, the seawater table and experimental apparatus received direct sunlight from noon until late in the afternoon.

Expt I was conducted over a period of $15 \mathrm{~d}$ from July 27 to August 10. During this period, daily UV-B measurements were provided (when available) by a Brewer UV Scanner at the Saturna Island Monitoring Station $\left(48^{\circ} 44^{\prime} \mathrm{N}, 123^{\circ} 8^{\prime} \mathrm{W}\right.$ ) on the eastern side of Vancouver Island. This scanner records 1 to 2 UV-B measurements per hour between sunrise and sunset (see Kerr \& McElroy 1993). The maximum midday UV intensity measured between 11:00 and 14:00 h each day was used to set an upper limit for conditions expected at Bamfield. Daily records of the number of hours of sunshine were also collected from the nearest weather station in Tofino $\left(49^{\circ} 07^{\prime} \mathrm{N}, 125^{\circ} 53^{\prime} \mathrm{W}\right.$ ) on the west coast of Vancouver Island. Capsules were checked daily for any change in their appearance and the water within each culture jar was replaced with freshly sterilized, antibiotic-treated seawater at 4 to 5 d intervals. The experiment was terminated on Day 15 following the appearance of a purple color in many of the stripped capsules exposed to UV Capsules were then opened individually and the numbor of live and dead embryos were counted. An embryo was considered dead (or dying) if there was evidence of: (1) tissue necrosis, (2) an extensive purple color associated with the visceral mass,
(3) the cessation of ciliary beating in the velar lobes, or (4) non-responsiveness to touch. Usually at least 2 or more of these characteristics were evident in dead embryos. Since velar cilia can be found beating even in detached portions of Nucella emarginata embryos (Rawlings pers, obs.), ciliary activity alone was not used to confirm embryonic survival. The presence/absence of protists within each capsule was also noted.

Expt II was conducted over a period of $24 \mathrm{~d}$ from August 15 to September 7 . All capsules used in this experiment were collected from Ross Islet and contained 2 nd-stage veligers or earlier developmental stages (see LeBoeuf 1971)

Statistical procedures. Parametric statistics were used where their assumptions could be met. Variances were compared for homogeneity prior to undertaking each analysis; in cases where variances were heterogeneous, the data were transformed (arcsine transformed for percentage data), and retested for homogeneity of variances. If variances were still heterogeneous, a parametric test allowing for heterogeneous variances was undertaken (e.g adjusted t-test, Sokal \& Rohlf 1981) or an equivalent non-parametric test was used.

\section{RESULTS}

\section{Survey of naturally deposited egg capsules of Nucella emarginata}

The availability of different microhabitats varied substantially among the 3 study sites (Fig. 2; hollow bars). At both Ross Islet and Wizard Islet, substantial algal cover $(>60 \%)$ was present, consisting mainly of Fucus gardneri and to a lesser extent Mastocarpus papillatus; this algal canopy was totally absent from Kirby Point. The availability of understorey microhabitats also differed among these sites, primarily in the amount of bare rock, turf algae, barnacles and mussels.

Microhabitats associated with Nucella emarginata capsules were not a random selection of those available (Fig. 2; hollow vs filled bars). Preferences of snails for specific microhabitats also differed substantially among sites (Table 1). At Ross Islet, snails selected areas for spawning that had a more extensive algal canopy, but a reduced amount of turf algae, relative to available habitats. At Wizard Islet, capsules were deposited in areas with more algal cover, Semibalanus cariosus, and bare rock, but a reduced cover of Mytilus spp. and Balanus glandula. Snails at Kirby Point, where there was nn aldgal ranopy. exhibited a significant preference for microhabitats with a greater cover of gooseneck barnacles Pollicipes polymerus and turf algae. 


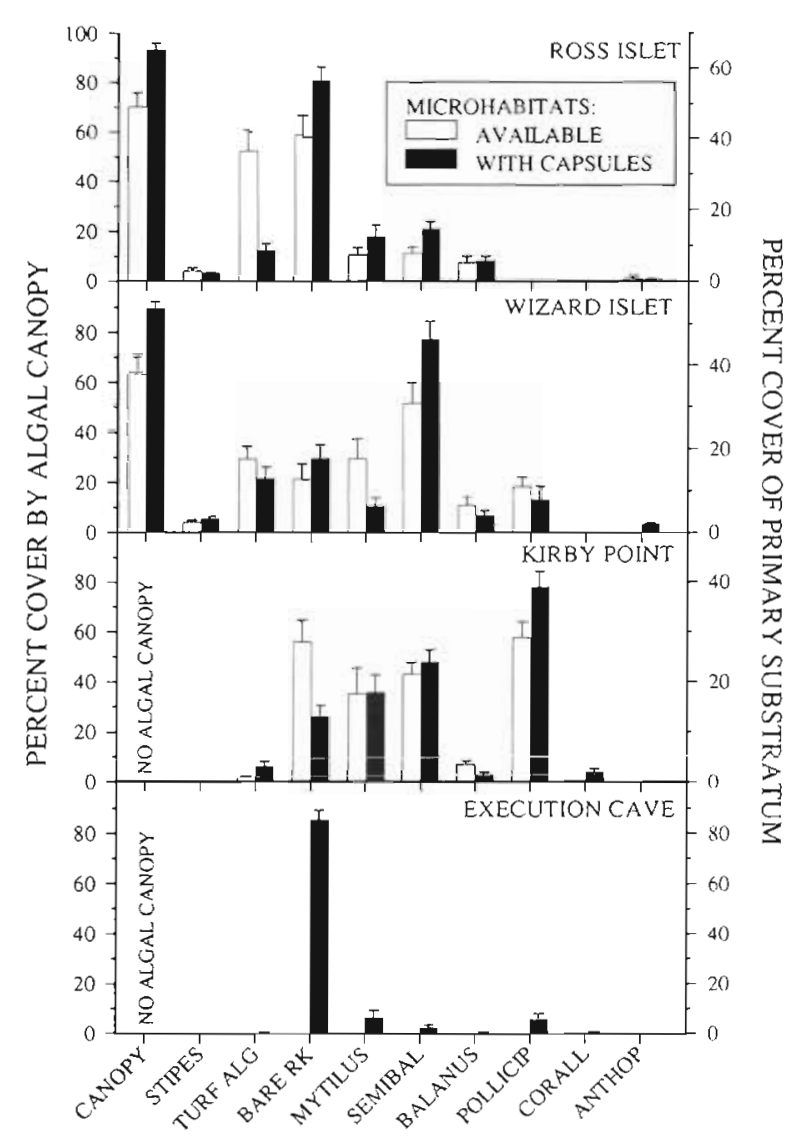

Although capsules were laid exclusively on bare rock or the shells of Semibalanus cariosus at all 3 sites, the frequency with which these substrata were used differed significantly among locations (Fig. 3). Under the algal canopy at Ross Islet, the majority of capsules were found on open, bare rock surfaces, with $<20 \%$ of capsules present in more sheltered habitats. Likewise. under the algal canopy at Wizard Islet, snails deposited their capsules almost exclusively on either bare rock surfaces or the outer surfaces of $S$. cariosus tests. At Kirby Point, there was a marked difference in the selection of substrata used for capsule deposition. Although barnacles and bare rock were each used
Fig. 2. Mean $( \pm \mathrm{SE})$ percentage cover of the primary substratum by algal canopy and understorey microhabitats in 20 'available' quadrats and in 20 quadrats associated with Nucella emarginata capsules at Ross Islet, Wizard Islet, and Kirby Point. Understorey microhabitats were broadly categorized as: Fucus stipes (STIPES); turf algae (TURF ALG); bare rock (BARE RK); mussels Mytilus spp., (MvTILUS); barnacles Semibalanus cariosus (SEMIBAL), Balanus glandula (BALANuS), and Pollicipes polymerus (poLlicip); encrusting coralline algae (CORALL); and anemones Anthopleura elegantissima (ANTHOP). The dotted vertical line separates measures of percentage cover of the algal canopy (left vertical axis) at each site from measures of percentage cover of understorey habitats (right vertical axis). At all 3 sites, the frequency of microhabitats associated with $N$. emarginata capsules differed from the frequency of microhabitats available at each location (G-test: Algal canopy: Ross: $G=195.59$, df $=1, p<0.001$; Wizard: $G=$ 199.52 , df $=1, p<0.001$, Primary substratum (minor habitats not included): Ross: $G=24.2 .09, \mathrm{df}=4, \mathrm{p}<0.001$; Wizard: $G=$ 112.97, $\mathrm{df}=5, \mathrm{p}<0.001$, Kirby: $G=143.84, \mathrm{df}=5, \mathrm{p}<0.001)$

with relatively equal frequency, the majority of capsules were squeezed next to other organisms or deposited within the protective confines of empty $S$. cariosus tests (see Fig. 4). Relatively few capsules were found on open rock surfaces.

Despite the lack of an algal canopy overlying Nucella emarginata capsules at Execution Cave, capsules were laid in areas with a very sparse covering of mussels and barnacles ( $<20 \%$ cover), and large areas of bare rock (Figs. $2 \& 3$ ). The majority of these capsules were deposited on completely exposed surfaces; fewer than $35 \%$ were nestled amongst other organisms.

Capsules also differed in their exposure to solar radiation among sites (Fig. 5). This difference largely reflected the presence and extent of the algal canopy overlying Nucella emarginata egg capsules. At Ross Islet and Wizard Islet, with an algal canopy covering $>90 \%$ of quadrats with capsules, $N$. emarginata capsules were well protected from direct radiation during periods of emersion. The lack of an algal canopy at Kirby Point, however, left capsules considerably more exposed to direct sunlight. Although snails at this site

Table 1. Non-significant subsets resulting from $G$-tests comparing the frequency of microhabitats (turf algae, bare rock, $M y t i l u s$ spp., Balanus glandula, Pollicipes polymerus, Semibalanus cariosus) used for capsule deposition by Nucella emarginata versus the frequency of those available. Separate $G$-tests were conducted for each study site. These a posteriori comparisons used a simultaneous test procedure

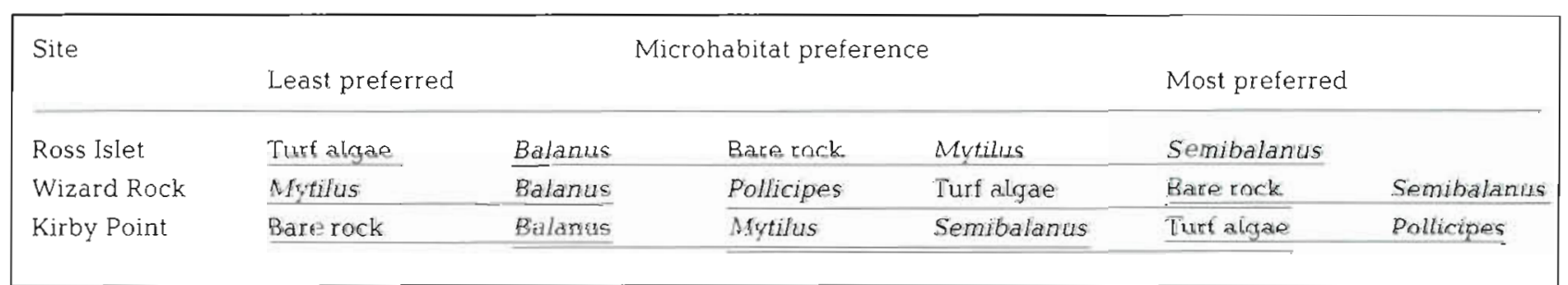



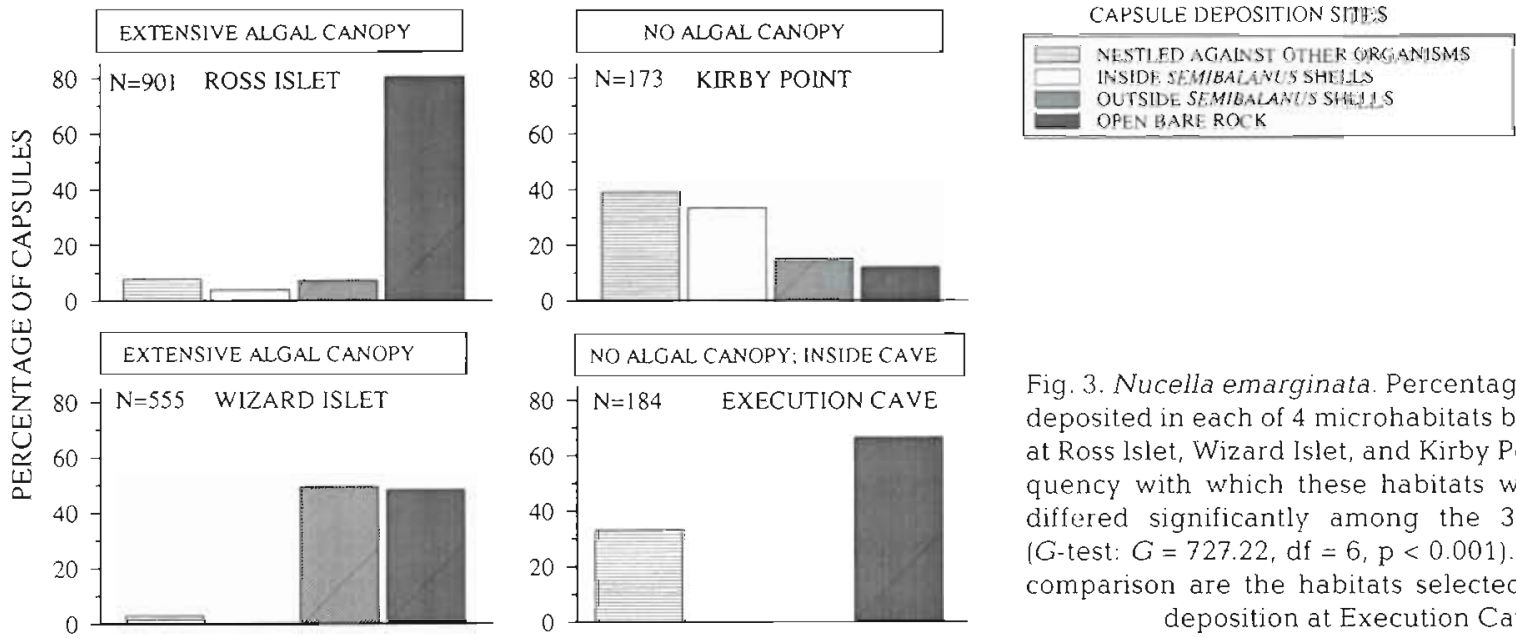

Fig. 3. Nucella emarginata. Percentage of capsules deposited in each of 4 microhabitats by individuals at Ross lslet, Wizard lslet, and Kirby Point. The frequency with which these habitats were selected differed significantly among the 3 study sites (G-test: $G=727.22, \mathrm{df}=6, \mathrm{p}<0.001)$. Included for comparison are the habitats selected for capsule deposition at Execution Cave

selected habitats likely to provide the most protection from desiccation and solar radiation (see Fig. 3), all capsule masses received some exposure to sunlight.

\section{Spectral properties of Nucella egg capsules}

Nucella emarginata capsule walls were relatively opaque to UV-B (280 to $320 \mathrm{~nm}$ ), but considerably more transparent to UV-A (320 to $400 \mathrm{~nm}$ ) (Fig. 6). The thick outer wall was chiefly responsible for this UV absorption. The spectral properties of capsules differed substantially among the 3 populations of $N$. emarginata sampled. Capsules collected from Ross Islet transmitted significantly more UV than capsules collected from either Grappler Inlet or Kirby Point (Fig. 7); these differences were marginally significant for UV-A and very significant for UV-B. Significant differences were also evident

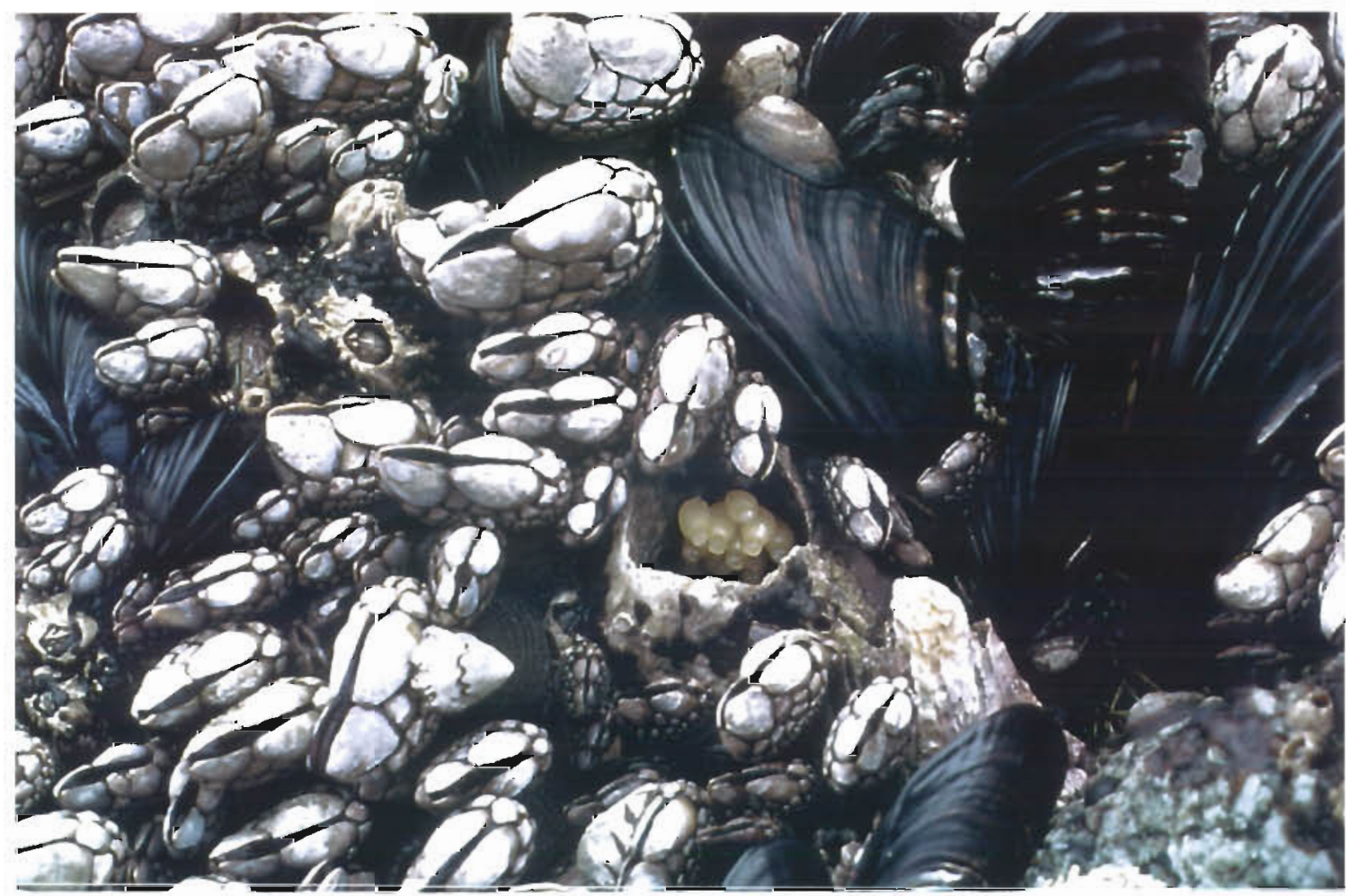

Fig. 4. Nucella emarginata. A group of egg capsules deposited in an empty test of the barnacle Semibalanus cariosus, at Kirby Point in August 1994. Note also the dense covering of the substratum by the gooseneck barnacle Pollicipes polymerus, and the lack of algal cover 


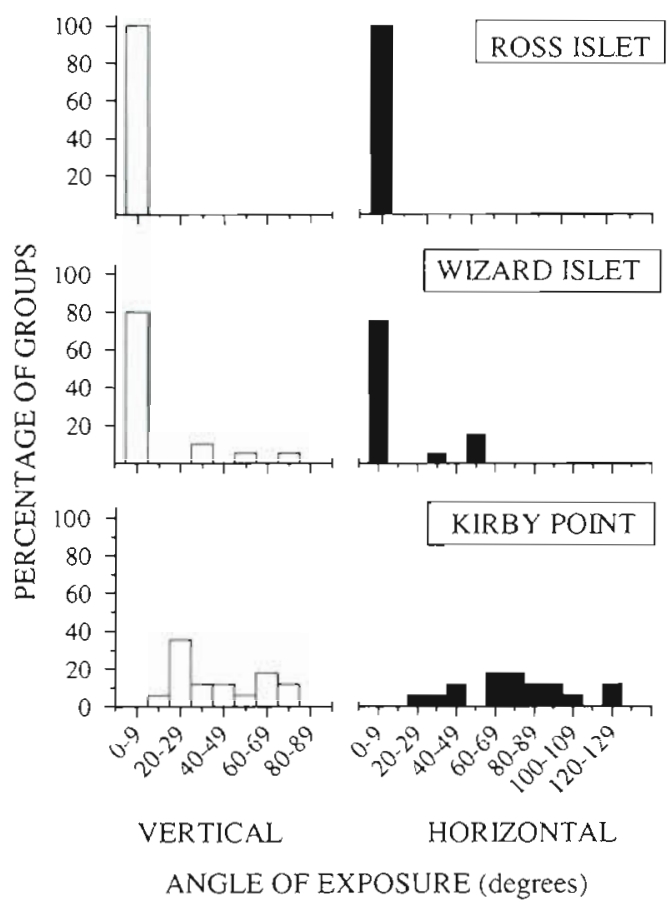

Fig. 5. Nucella emarginata. Potential exposure (vertucal and horizontal) of naturally deposited groups of capsules to direct sunlight at Ross Islet ( $n=20$ groups), Wizard Islet $(n=20)$, and Kirby Point $(\mathrm{n}=17)$. Measurements are explained in Fig. 1. Exposure of capsules to direct solar radiation differed significantly among sites: vertical angle of exposure (frequency categories: $0-20,20-40,40-60,60-80: G=41.47, \mathrm{df}=6, \mathrm{p}<$ 0.001 ) , horizontal angle of exposure (frequency categories: $0-30,30-60,60-90,90-130: G=50.86, d f=6, p<0.001)$. The mean $( \pm \mathrm{SE})$ compass bearing for capsule groups sampled at Kirby Point was $181.9^{\circ} \mathrm{S} \pm 3.76^{\circ}(\mathrm{n}=17)$

among the spectral properties of $N$. emarginata (Kirby Point), N. lamellosa (Grappler Inlet) and $N$. canaliculata (Kirby Point) capsules: $N$. lamellosa capsules were more transparent to UV than either $N$. emarginata or $N$. canaliculata capsules (Fig. 8). N. lamellosa capsules also allowed significantly more UV to enter the capsule chamber than even the most transparent $N$. emarginata capsules from Ross Islet [2-way nested ANOVA for each wavelength: $360 \mathrm{~nm}$ UV-A: $F$ (population) $=6.69$, $\mathrm{df}=1,14, \mathrm{p}<0.025 ; 300 \mathrm{~nm}$ UV-B: $F$ (population) $=14.73$, $\mathrm{df}=1,14, \mathrm{p}<0.01)]$.

UV transmittance declined exponentially as a function of depth within the outer wall of Nucella emarginata capsules. Over $90 \%$ of incident $300 \mathrm{~nm}$ UV-B was absorbed within the outer half of the wall (Fig. 9). Despite this, there was no polarity to the UV-absorbing properties of this wall; light transmittance profiles were almost identical regardless of whether the outer wall was oriented forwards or backwards with respect to the light source. The percent transmittance of UV also varied similarly with depth within the outer walls

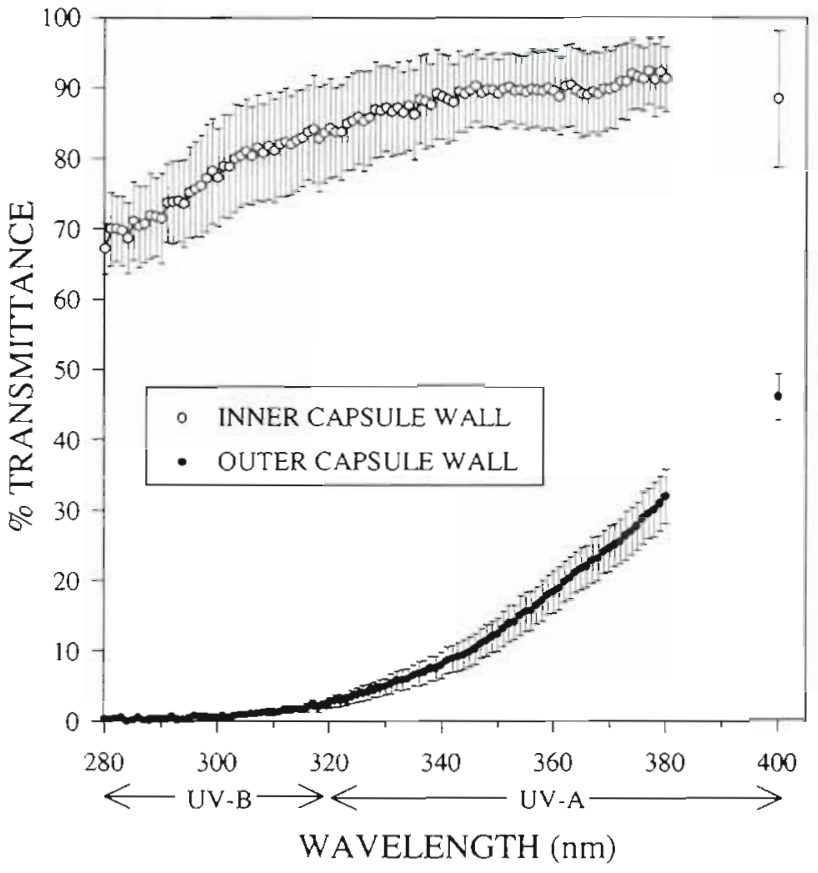

Fig. 6. Nucella emarginata. Spectral properties of the inner and outer wall of capsules from a laboratory population (mean $\%$ transmittance $\pm \mathrm{SE} ; \mathrm{n}=3$ capsules). Two separate $t$-tests (adjusted for heterogeneous variances) compared the \% transmittance of UV across the inner and outer capsule wall for representative wavelengths of $360 \mathrm{~nm}$ UV-A and $300 \mathrm{~nm}$ UV-B. The inner capsule wall was more transparent to UV-A (360 nm: $\left.t^{\prime}=9.114, \mathrm{df}=2, \mathrm{p}<0.02\right)$ and UV-B $(300 \mathrm{~nm}: t=$ $12.580, \mathrm{df}=2, \mathrm{p}<0.01$ )

of $N$. canaliculata and $N$. lamellosa capsules (Fig. 9). Differences in the spectral properties of capsules among Nucella spp. thus appeared to reflect differences in the thickness of the outer wall.

Attempts to extract UV-absorbing compounds from the capsule wall using $80 \%$ methanol proved unsuccessful. A 2-factor ANOVA compared the effect of extraction solvent (i.e. methanol vs water) and capsule source ( 5 different capsules) on the transmittance of $360 \mathrm{~nm}$ UV-A and $300 \mathrm{~nm}$ UV-B across the capsule wall. Solvent treatment had no significant effect on the transmittance of either UV-A [ANOVA: $F$ (solvent) $=$ 2.502, $\mathrm{df}=1,4, \mathrm{p}>0.10, F$ (capsule $)=3.115, \mathrm{df}=4,20$, $\mathrm{p}=0.04]$ or UV-B [ $F$ (solvent) $=0.357, \mathrm{df}=1,4, \mathrm{p}>0.50$; $F$ (capsule) $=4.264, \mathrm{df}=4,20, \mathrm{p}=0.01\}$, although the spectral properties of different capsules did vary significantly.

\section{Vulnerability of encapsulated embryos to ultraviolet radiation}

Expt I. There was an average of $5.5 \pm 1.51 \mathrm{~h}$ (mean \pm SE) of sunshine per day during this $15 \mathrm{~d}$ experiment. 


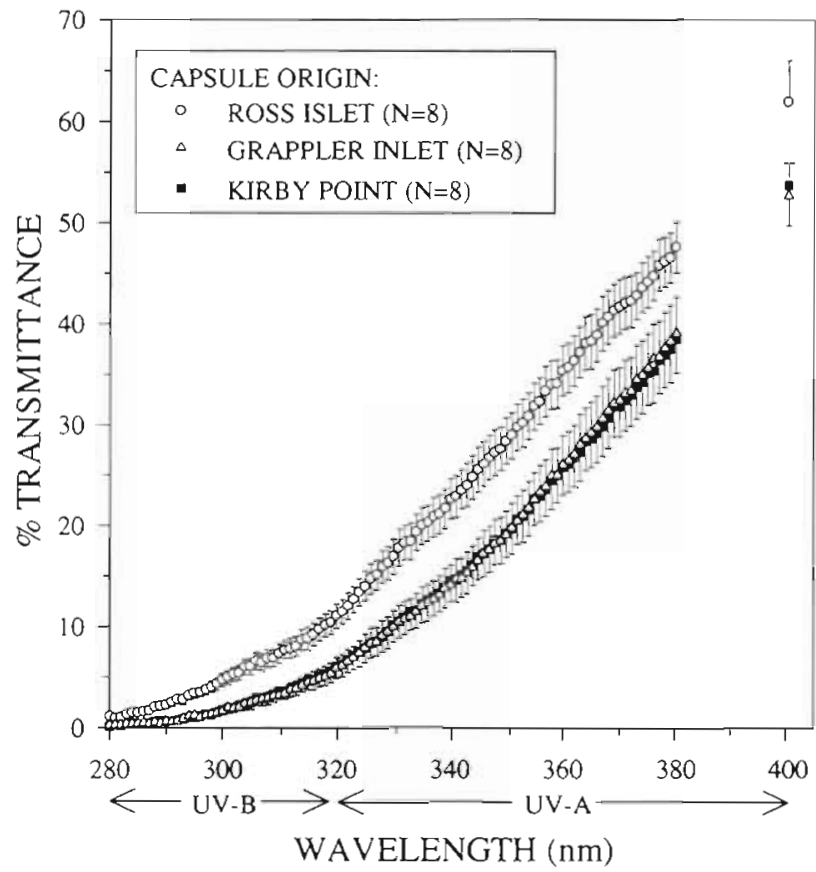

Fig. 7. Nucella emarginata. Spectral properties of capsules (mean $\%$ transmittance \pm SE) from 3 different populations ( $\mathrm{n}=8$ capsules per site). Percent transmittance of $360 \mathrm{~nm}$ UV-A and $300 \mathrm{~nm}$ UV-B was compared among populations using a 2-level nested ANOVA. There was a significant effect of source population and capsule for both wavelengths: UVA: $F$ (population) $=3.234, \mathrm{df}=2,21,0.05<\mathrm{p}<0.1 ; F$ (capsule) $=8.780, \mathrm{df}=21,48, \mathrm{p}<0.001 \mathrm{i}$ UV-B: $F($ population $)=7.357$. $\mathrm{df}=2,21, \mathrm{p}<0.01 ; F($ capsule $)=13.290, \mathrm{df}=21,48, \mathrm{p}<0.001$ A posteriori comparisons indicated that Ross Islet capsules were significantly more transparent to UV-A $(\alpha=0.1)$ and UV-B $(\alpha=0.05)$ than either Grappler Inlet or Kirby Point capsules

This included $5 \mathrm{~d}$ with more than $8 \mathrm{~h}$ of sunshine, $3 \mathrm{~d}$ with 4 to $8 \mathrm{~h}$ of sunshine, and $7 \mathrm{~d}$ with less than $4 \mathrm{~h}$ of direct sunshine. The average midday-maximum UV-B intensity for Saturna Island over this experimental period was $156874 \pm 9.9013 \mathrm{~mW} \mathrm{~m}^{-2}$ (mean $\pm \mathrm{SE}_{\text {; }}$ $\mathrm{n}=14$ ).

Despite relatively few days with prolonged sunshine, sunlight treatment had a significant effect on embryonic survival (Fig. 10, Table 2): embryos in capsules exposed to UV suffered substantially higher mortality than those in dark or UV-filtered treatments. Of those capsules expased to UV, embryos in stripped capsules had significantly lower survivorship than those in whole capsules. Of 129 embryos within stripped capsules that died during exposure to UV radiation, 78.3\% exhibited a strong purple coloration indicative of physiological stress (sce Spight 1977, Pechenik 1982, 1983) This change in coloration was never seen in embryos exposed to other light treatments, or in embryos within whole capsules.

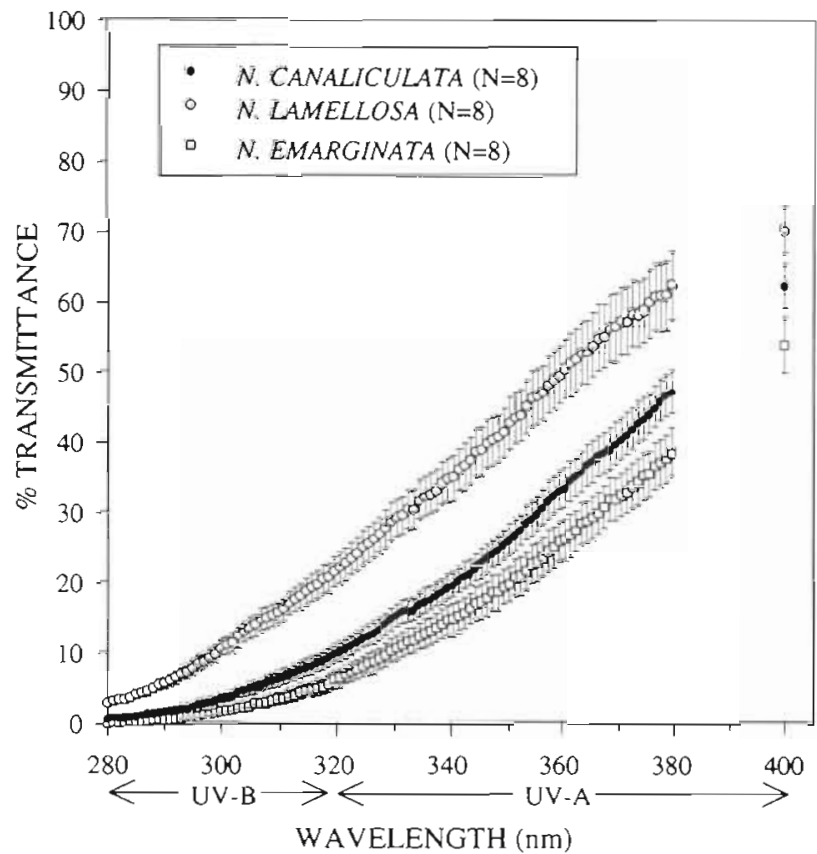

Fig. 8. Spectral properties of Nucella emarginata (Kirby Point), N. lamellosa (Grappler Inlet), and $N$ canaliculata (Kirby Point) capsules (mean $\pm \mathrm{SE}, \mathrm{n}=8$ capsules per species). Percent transmittance of $360 \mathrm{~nm}$ UV-A and $300 \mathrm{~nm}$ UV-B was compared using a 2-level nested ANOVA. Both source species and capsule origin had a significant effect for both wavelengths: UV-A: $F$ (species) $=8.75, \mathrm{df}=2.21, \mathrm{p}<0.01 ; F$ (capsule $)=6.34, \mathrm{df}=21,47, \mathrm{p}<0.001 ; \mathrm{UV}-\mathrm{B}:$ F(species $)=44.62$, $\mathrm{df}=2,21, \mathrm{p}<0.001 ; F($ capsule $)=8.48, \mathrm{df}=21,47, \mathrm{p}<0.001$ A postenori comparisons indicated that $N$. Iamellosa capsules were significantly more transparent to UV-B and UV-A than either $N$. canaliculata or $N$. emarginata capsules $(\alpha=0.05)$; no significant difference was found between $N$. canaliculata and $N$. emarginata capsules

Among-treatment differences in embryonic mortality were unlikely to have resulted from differences in water temperature. Repeated measurements of water temperature within the culture chambers during the mid-late afternoon of warm sunny days did not reveal any substantial differences among treatment conditions [e.g. Aug 2: Dark: $12.3 \pm 0.14^{\circ} \mathrm{C}$ i UVfiltered: $12.5 \pm 0.20^{\circ} \mathrm{C}$; UV-exposed: $12.4 \pm 0.24^{\circ} \mathrm{C}$ $(\mathrm{n}=4$ replicates $)\}$.

Expt II. Capsules experienced considerably more days of sunshine over the $23 \mathrm{~d}$ of Expt II: $12 \mathrm{~d}$ of $>8 \mathrm{~h}$ sunshine, $4 \mathrm{~d}$ with 4 to $8 \mathrm{~h}$ sunshine, and $7 \mathrm{~d}$ with $<4 \mathrm{~h}$ sunshine. Although the average number of hours of sunshine per day was higher for this experiment (mean $\pm \mathrm{SE} ; 6.7 \pm 0.97 \mathrm{~h}$ ), the average midday-maximum UV$B$ reading over this period was lower than that resnrded for Expt I [ $128.795 \pm 4.2232 \mathrm{~mW} \mathrm{~m}^{-2}$ imean \pm $\mathrm{SE}, \mathrm{n}=19)$ ].

The percentage of embryos surviving exposure to different sunlight treatments was generally lower in 


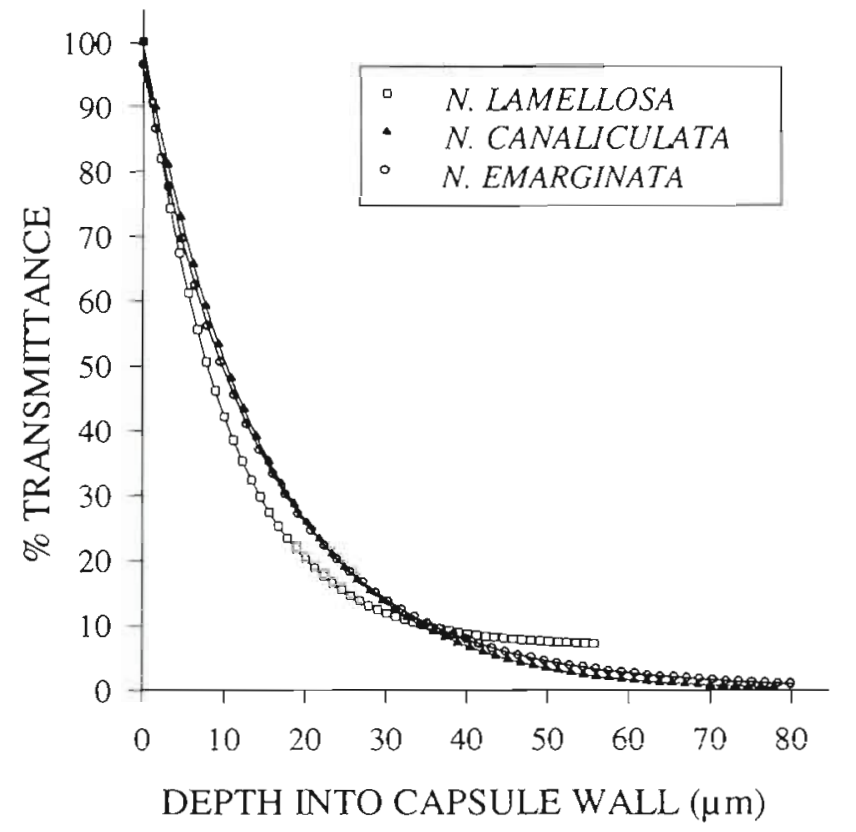

Fig. 9. Mean percent transmittance of $300 \mathrm{~nm}$ UV-B at various depths into the outer wall of Nucella lamellosa $(n=1), N$. canaliculata $(n=3)$, and $N$. emarginata capsules $(n=3)$. The mean thickness of the outer wall was 56,78 and $80 \mu \mathrm{m}$ for $N$. lamellosa, $N$. canaliculata, and $N$. emarginata capsules, respectively

Expt II (Fig. 10, Table 2). One series of replicates had to be terminated because cultures became contaminated with protists which killed embryos within most stripped capsules; no other cultures were contaminated, however. In the remaining replicates, embryonic mortality was significantly affected by sunlight treatment: survival was significantly lower in the UVexposed treatment versus the dark and UV-filtered treatments. Although capsule wall treatment (stripped vs whole) had no significant effect on embryo survival, mortality was considerably higher in stripped capsules exposed to UV than in whole capsules. A 2-way non-

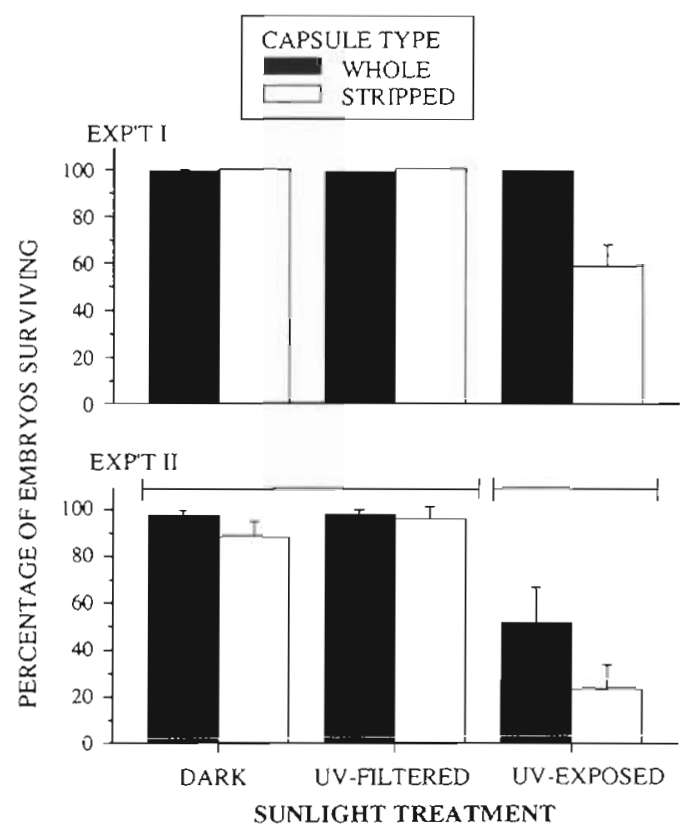

Fig. 10. Nucella emarginata. Percentage (mean $\pm \mathrm{SE}$ ) of embryos within stripped and whole capsules that survived exposure to 3 different sunlight treatments in Expts $I$ ( $n=4$ jars treatment ${ }^{-1}$ ) and $\left[1\right.$ ( $n=3$ jars treatment $\left.{ }^{-1}\right)$. Capsules were exposed to treatment conditions of 15 and $23 \mathrm{~d}$ in Expts I and II, respectively. Results of a 2-way non-parametric ANOVA comparing the \% of embryos surviving each treatment condition are as follows: Expt I: $\chi^{2}$ (cap wall) $=0.24, \mathrm{df}=$ $1, p>0.50 ; \chi^{2}$ (sunlight) $=6.971, \mathrm{df}=2, \mathrm{p}<0.05 ; \chi^{2}$ (interaction $)=8.091, \mathrm{df}=2, \mathrm{p}<0.025$. Expt II: $\chi^{2}$ (cap wall $)=0.333$, $\mathrm{df}=1, \mathrm{p}>0.50 ; \chi^{2}$ (sunlight) $=12.150, \mathrm{df}=2, \mathrm{p}<0.01 ; \chi^{2}$ (interaction $)=0.361, \mathrm{df}=2, \mathrm{p}>0.50$. Connecting horizontal lines above the results of Expt II indicate non-significant differences among treatment conditions

parametric ANOVA comparing embryo survival within stripped and whole capsules exposed to UV in Expts I and II revealed both a significant effect of the capsule wall (stripped vs whole: $\chi^{2}=3.92, \mathrm{df}=1, \mathrm{p}<0.05$ ) and a significant difference among experiments (Expt I vs II $\chi^{2}=4.82$, df $=1, p<0.05$ ).

Table 2. Percentage (mean $\pm \mathrm{SE}$ ) of embryos surviving within jars containing 6 whole and 6 stripped capsules when exposed to 1 of 3 different sunlight treatments in 2 separate outdoor experiments

\begin{tabular}{|c|c|c|c|c|c|c|}
\hline & \multicolumn{2}{|c|}{ Dark } & \multicolumn{2}{|c|}{ UV filtered } & \multicolumn{2}{|c|}{ UV exposed } \\
\hline & Whole & Stripped & Whole & Stripped & Whole & Stripped \\
\hline \multicolumn{7}{|l|}{ Expt 1} \\
\hline $\operatorname{Jar} 1$ & $98.0 \pm 1.24$ & $100.0 \pm 0.0$ & $99.0 \pm 0.98$ & $100.0 \pm 0.0$ & $99.3 \pm 0.67$ & $71.7 \pm 17.89$ \\
\hline Jar 2 & $100.0 \pm 0.0$ & $100.0 \pm 0.0$ & $100.0 \pm 0.0$ & $100.0 \pm 0.0$ & $98.9 \pm 1.12$ & $64.4 \pm 20.48$ \\
\hline $\operatorname{Jar} 3$ & $100.0 \pm 0.0$ & $100.0 \pm 0.0$ & $98.4 \pm 1.06$ & $100.0 \pm 0.0$ & $100.0 \pm 0.0$ & $65.8 \pm 12.11$ \\
\hline $\operatorname{Jar} 4$ & $100.0 \pm 0.0$ & $100.0 \pm 0.0$ & $98.1 \pm 1.34$ & $100.0 \pm 0.0$ & $99.3 \pm 0.72$ & $31.0 \pm 9.08$ \\
\hline \multicolumn{7}{|l|}{ Expt II } \\
\hline Jar 1 & $97.0 \pm 1.96$ & $83.3 \pm 16.70$ & $93.8 \pm 6.25$ & $84.9 \pm 8.75$ & $46.4 \pm 20.98$ & $32.5 \pm 20.56$ \\
\hline $\operatorname{Jar} 2$ & $100.0 \pm 0.0$ & $98.6 \pm 1.38$ & $97.3 \pm 2.67$ & $100.0 \pm 0.0$ & $27.3 \pm 17.32$ & $1.0 \pm 0.98$ \\
\hline $\operatorname{Jar} 3$ & $92.9 \pm 7.15$ & $80.0 \pm 20.00$ & $100.0 \pm 0.0$ & $100.0 \pm 0.0$ & $78.9 \pm 15.90$ & $33.3 \pm 21.08$ \\
\hline
\end{tabular}




\section{DISCUSSION}

Structurally complex benthic egg capsules or gelatinous egg ribbons may protect developing embryos from a variety of environmental risks associated with a benthic existence (see review in Pechenik 1986), yet their resistance to UV has rarely been examined (but see Biermann et al. 1992). The results of the present study illustrate not only that egg capsules of Nucella emarginata can be exposed to appreciable amounts of solar radiation under natural conditions, but also that their capsule walls act to shield embryos from the potentially lethal effects of UV-B. Thus, these findings demonstrate an additional protective role for the capsules of benthic marine gastropods.

\section{Selection of spawning habitats by Nucella emarginata}

Many species of neogastropods exhibit a remarkable specificity for certain spawning habitats. Individuals of Nucella lamellosa, for instance, often return to the same spawning locations year after year (Spight 1974). In other species, the lack of 'suitable' substrata for spawning may limit reproduction entirely (Brenchley 1981). Despite this specificity, however, the role that biological (predation) and physical (desiccation, heat stress, UV) factors play in the selection of spawning habitats remains poorly understood. Although areas exposed to direct solar radiation may be less favored for spawning by many marine gastropods (e.g. Emlen 1966, Gallardo 1979, Biermann et al. 1992, this study), this may not reflect avoidance of UV specifically. Higher wavelength radiation, desiccation and heat stress are all associated with increased solar radiation, and hence could also be selective forces influencing the preference of gastropods for shaded spawning areas.

Physical stresses undoubtedly influence the selection of spawning habitats by Nucella emarginata. At Execution Cave, where environmental stresses such as UV, desiccation, and heat stress were likely to be low relative to other sites, the majority of capsules were laid in areas unprotected from these stresses. At other sites, where these stresses were severe, the selection of spawning sites depended on the presence of an algal canopy. Where a thick algal canopy was available, snails deposited capsules within the moist, shaded confines of this canopy. At more wave-exposed locales, which typically lack an extensive canopy (see Menge 1978, this study), snails laid capsules within harnacle tests or near clumps of Pollicipes polymerus; capsules within these habitats remained moist during emersion, but were considerably more open to direct solar radia- tion. Because wave-exposed populations of $N$. emarginata in Barkley Sound spawn primarily in the spring and summer months (Gosselin 1994, Rawlings unpubl. data), and because these populations persist from year to year, embryos of this species appear able to tolerate periods of direct exposure of their capsules to UV. Thus, exposure to UV appears unimportant in the selection of spawning sites by this species. In contrast, desiccation stress is likely to be a frequent source of mortality for embryos of Nucella spp. (Feare 1970, Spight 1977, Rawlings unpubl. data). Although encapsulated embryos can withstand up to $80 \%$ water loss from the capsule chamber, capsules desiccate quickly under summer field conditions unless protected by an algal canopy (Rawlings 1995a) or other moist habitats. Avoidance of desiccation stress may thus explain the preference of $N$. emarginata for the spawning habitats selected in this study.

\section{Spectral properties of Nucella egg capsules}

The leathery capsules of Nucella emarginata provided embryos with substantial protection from UV, allowing $<5 \%$ of incident $300 \mathrm{~nm} \mathrm{UV-B}$ and $<55 \%$ of incident $360 \mathrm{~nm}$ UV-A to cross the capsule wall. $N$. lamellosa, and $N$. canaliculata capsules also absorbed a high percentage of incident UV-B. Other types of gastropod egg coverings, however, may not be such effective UV shields. For instance, Biermann et al. (1992) found that the egg mass jelly of the dorid nudibranch Archidoris montereyensis provided embryos with little protection from mortality associated with exposure to direct solar radiation, although embryos embedded deeper within these egg masses did experience higher survival relative to peripheral embryos (Biermann et al. 1992). Differences in the protective nature of these encapsulating structures may result from variation in their material composition. Within one subclass of Gastropoda alone (e.g. the Prosobranchia), egg coverings vary substantially in morphology (i.e. size, shape, surface texture), chemical composition, and structure (i.e. leathery vs gelatinous), yet the relative merits of these properties as shields against UV are unknown.

The mechanism by which Nucella capsules shield embryos from UV remains unclear. In terrestrial plants, leaf surface reflectance provides a first line of defense against UV (Gausman et al. 1975, Robberecht et al. 1980). Given the profiles of UV transmittance through the capsule walls of Nucella spp., however, surface srattering is unlikely to he extensive relative to absorption by the capsule wall itself. In plants, UV transmittance is also inversely correlated with the thickness of the epidermis (Day 1993). This appears true for cap- 
sules of Nucella spp.: capsules collected from Grappler Inlet and Kirby Point, where snails lay thicker-walled capsules (Rawlings 1994), absorbed significantly more UV-A and UV-B than thinner-walled capsules from Ross Islet. Interspecific differences in the spectral properties of Nucella capsules also reflected the same trend. Thinner-walled capsules of $N$. lamellosa (Rawlings unpubl. data) were significantly more transparent to UV than the thicker-walled capsules of. N. canaliculata and $N$. emarginata. Absorption of UV did not vary among the different microstructural regions comprising the outer wall of these capsules, however (see Rawlings 1995b). Thus, the UV-absorbing properties of Nucella capsules appear associated with some general component of the outer capsule wall itself.

Despite the prevalence of MAAs as biochemical defenses against UV in many marine organisms (Karentz et al. 1991), these amino acids were not present in the capsules of Nucella emarginata. The soaking of capsule pieces in methanol for over 10 times the length of time required for $99 \%$ extraction of MAAs from minced tissues (Karentz et al. 1991) had no significant effect on UV transmittance. While MAAs have been extracted from a variety of Antarctic marine gastropods, including the muricid snail Trophon cf. geversianus, attempts to extract MAAs from whole capsules (including eggs) of Trophon cf. geversianus have proved fruitless (Karentz et al. 1991). Likewise, only trace amounts of 1 MAA have been found in the benthic egg ribbons of an unidentified nudibranch (Karentz et al. 1991). MAAs are present in the eggs of limpets and fish species with planktonic development (Chioccara et al. 1980, Karentz et al, 1992), however, perhaps reflecting differences in the exposure of freely developing embryos and larvae to UV versus those confined within protective coverings (see Karentz 1994).

What then is responsible for absorbing UV radiation within the walls of Nucella egg capsules? Although neogastropod egg capsules are composed mainly of protein and carbohydrate produced by a capsule gland in the oviduct (e.g. Hunt 1966. Bayne 1968, Hunt 1971, Flower 1973, Sullivan \& Maugel 1984, Hawkins \& Hutchinson 1988), their UV-absorbing properties may be associated with compounds produced in the ventral pedal gland that cross-link capsule proteins (see Price \& Hunt 1973, 1974, 1976). Price \& Hunt (1973) first noted that capsules of the neogastropod Buccinum undatum fluoresced a blue-white light when exposed to UV. Subsequent investigation indicated that this fluorescence resulted from the presence of a yellow fluorophore covalently bound to peptjdes within the capsule wall (Price \& Hunt 1974). Examinations of both the fluorophore and secretions of the ventral pedal gland suggest that this substance contains aromatic aldehydes and proteins, but further characterization has been unsuccessful (Price \& Hunt 1974, 1976). While similar UV-fluorescing compounds have not been described for Nucella egg capsules specifically, given the yellow color of these capsules, and their similar chemical properties to Buccinum capsules, the UV absorption of Nucella capsules may also result from fluorophores within the capsule wall.

\section{Significance of the capsule wall as a barrier to UV radiation}

Even though capsule walls may filter a large proportion of incident UV, this does not necessarily imply that this absorption is biologically significant. A substantial fraction of potentially lethal UV-B radiation still enters the chamber of even the thickest-walled Nucella emarginata capsules. Likewise, UV-A has some deleterious consequences for aquatic organisms (e.g. Smith et al. 1992), yet its passage across the capsule walls of Nucella spp. is relatively unhindered compared to UVB. Given these facts, is the capsule wall really a biologically significant barrier to UV?

The results of outdoor experiments using stripped and whole Nucella emarginata capsules indicate that capsule walls are indeed biologically significant UV filters. While capsules were likely exposed to higher doses of UV than they would experience under normal field conditions, these experiments illustrate an important point. The absorption of UV by outer capsule walls can mean the difference between survival and death for encapsulated embryos. Embryos devoid of this barrier suffered substantially higher mortality when exposed to natural solar radiation compared to embryos within whole capsules, or those in stripped capsules not exposed to UV. Although some embryos did die in whole capsules exposed to UV in Expt II, this difference among experiments could reflect variation in the source population of capsules (i.e. thick-walled lab-laid capsules vs thin-walled Ross Islet capsules for Expts I and II, respectively), differences in the tolerances of early-versus late-stage embryos to UV, or simply differences in the duration and intensity of UV exposure between these experiments. Nevertheless, embryos in stripped capsules exposed to UV did exhibit higher mortality in both experiments.

The relatively low absorption of UV-A by the capsule walls of Nucella spp. may reflect differences in the amount of biological damage caused by UV-A versus UV-B radiation. Although UV-A can have a negative effect on photosynthetic organisms by causing photoinhibition in phytoplankton (e.g. Helbling et al. 1992, Smith et al. 1992 and references therein), the great variability of responses among marine organisms to 
UV-A has led some to believe that this form of radiation is not a unique or very important environmental factor (Damkaer et al. 1980). In fact, exposure to UV-A may even be beneficial to many organisms. Some species are able to detect UV-A and use it as a cue for avoiding exposure to the more harmful UV-B (Bothwell et al. 1994, and references therein). Likewise, the presence of UV-A can be critical to the successful photoenzymatic repair of DNA damaged as the result of exposure to UV-B (e.g. Karentz et al. 1991, Smith et al. 1992). Hence, UV-A exposure may be far less detrimental to non-photosynthetic marine organisms than. exposure to UV-B.

Positive associations between the exposure of organisms to UV and the presence of effective defenses against UV also provide strong evidence for the biological significance of such defense mechanisms. In many species, higher concentrations of MAAs are found in those organisms with a greater exposure to UV (e.g. Dunlap et al. 1986, Shick et al. 1992). Likewise, the ability of amphibian eggs to repair UV-damaged DNA is enhanced in species with an increased likelihood of exposure to sunlight during development (Blaustein et al. 1994). Variation in the wall thickness and UV-absorbing properties of Nucella lamellosa, $N$. canaliculata and $N$. emarginata capsules is also consistent with the frequency of exposure of these capsules to UV. Typically, N. lamellosa has a lower intertidal distribution than either $N$. canaliculata and $N$. emarginata (Palmer 1980), thus resulting in a shorter duration of exposure of capsules to direct sunlight. $N$. lamellosa capsules collected from Grappler Inlet are also thinner-walled and significantly more transparent to UV than capsules of the other 2 Nucella species. The inclusion of other potential differences (e.g. spawning season, spawning sites, reproductive patterns) in a comparative study of capsule properties within and among Nucella species could thus further clarify the role that these benthic egg capsules play in protecting embryos from UV.

Acknowledgements. I thank the Director and staff at the Bamfield Marine Station for providing such fine facilities, and T C. Vogelmann for welcoming me into his laboratory in Wyomıng. The Atmospheric Environmental Service of Environment Canada provided climatic data from the Saturna Island UV Monitoring Station and Tofino Weather Station. Comments from J. Dalby Jr, L. Gosselin, A. Kohn, A. R. Palmer, J. M. Shick, A. N. Spencer, T C. Vogelmann, and 2 anonymous reviewers improved this manuscript. This study was supported in part by a Research Grant in Malacology from the Western Society of Malacologists, Santa Barbara Shell Club. Northern California Malacozooloqical Club, and San Diego Shell Club, and a Province of Alberta Graduate Fellowship to T.A.R. Additional support was provided by an NSERC operating grant to A.R. Palmer, and an NSF grant (IBN-94-09139) to T. C. Vogelmann.

\section{LITERATURE CITED}

Bayne CJ (1968) Histochemical studies on the egg capsules of eight gastropod molluscs. Proc Malac Soc Lond 38: $199-212$

Biermann $\mathrm{CH}$, Schinner GO, Strathmann RR (1992) Influence of solar radiation, microalgal fouling, and current on deposition site and survival of embryos of a dorid nudibranch gastropod. Mar Ecol Prog Ser 86: $205-215$

Blaustein AR, Hoffman PD, Hokit DG, Kiesecker JM, Walls SC. Hays JB (1994) UV repair and resistance to solar UV-B in amphibian eggs: a link to population declines? Proc Natl Acad Sci ISA 91:1791-1795

Bothwell ML, Sherbot DMJ, Pollock CM (1994) Ecosystem response to solar ultraviolet- $B$ radiation: influence of trophic-level interactions. Science 265:97-100

Brenchley GA (1981) Limiting resources and the limits to reproduction in the 'mud' snail Ilyanassa obsoleta in Barnstable Harbor, Massachusetts. Biol Bull 161:323

Brenchley GA (1982) Predation on encapsulated larvae by adults: effects of introduced species on the gastropod Ilyanassa obsoleta. Mar Ecol Prog Ser 9:255-262

Chioccara F, Della Gala A, de Rosa M, Novellino E, Prota G (1980) Mycosporine amino acids and related compounds from the eggs of fishes. Bull Soc Chim Belg 89: $1101-1106$

Damkaer DM, Dey DB (1982) Short term responses of some planktonic Crustacea exposed to enhanced UV-B radiation. In: Calkins J (ed) The role of solar ultraviolet radiation in marine ecosystems. Plenum Press, New York, p 417-427

Damkaer DM, Dey DB (1983) UV damage and photoreactivation potentials of larval shrimp, Pandalus platyceros, and adult euphausiids, Thysanoessa raschii. Oecologia 60:169-175

Damkaer DM, Dey DB, Heron GA, Prentice EF (1980) Effects of UV-B radiation on near-surface zooplankton of Puget Sound. Oecologia 44:149-158

Day TA (1993) Relating UV-B radiation screening effectiveness of foliage to absorbing-compound concentration and anatomical characteristics in a diverse group of plants. Oecologia 95:542-550

Day TA, Vogelmann TC, DeLucia EH (1992) Are some plant life forms more effective than others in screening out ultraviolet-B radiation? Oecologia 92:513-519

Dunlap WC, Chalker BE, Oliver JK (1986) Bathymetric adaptations of reef-building corals at Davies Reef, Great Barrier Reef, Australia. III. UV-B absorbing compounds. J Exp Mar Biol Ecol 104:239-248

Emlen JM (1966) Time, energy and risk in two species of carnivorous gastropods. PhD dissertation, Unıv of Washington, Seattle

Feare CJ (1970) Aspects of the ecology of an exposed shore population of dogwhelks Nucella lapillus (L.). Oecologia 5:1-18

Flower NE (1973) The storage and structure of proteins used in the production of egg capsules by the mollusc Cominella maculosa. J Ultrastruct Res 44:134-145

Fretter V, Graham A (1962) British Prosobranch molluscs. Ray Society, London

Gallardo CS (1979) Developmental pattern and adaptations for reproduction in Nucella crassilabrum and other muricacean gastropods. Biol Bull 157:453-463

Gausman RW, Rodriguez RP, Fscobar DE (1975) Ultraviolet radiation reflectance, transmittance, and absorbance by plant leaf epidermıses. Agron J 83:391-396 
Giese AC, Pearse JS (1974) Reproduction of manne invertebrates, Vol 1. Acoelomate and pseudocoelomate metazoans. Academic Press, New York

Gosselin LA (1994) Ecology of early juvenile Nucella emarginata (Gastropoda; Prosobranchia): are hatchling snails simply small adults? PhD dissertation, University of Alberta, Edmonton

Hawkins LE, Hutchinson S (1988) Egg capsule structure and hatching mechanism of Ocenebra erinacea (L.) (Prosobranchia: Muricidae). J Exp Mar Biol Ecol 119: 269-283

Helbling EW, Villafañe V, Ferrario M, Holm-Hansen O (1992) Impact of natural ultraviolet radiation on rates of photosynthesis and on specific marine phytoplankton species. Mar Ecol Prog Ser 80:89-100

Herndl GJ, Müller-Niklas G, Frick J (1993) Major role of ultraviolet-B in controlling bacterioplankton growth in the surface layer of the ocean. Nature 361:717-719

Hunt S (1966) Carbohydrate and amino-acid composition of the egg capsule of the whelk Buccinum undatum $\mathrm{L}$. Nature 210:436-437

Hunt S (1971) Comparison of the three extracellular structural proteins in the gastropod mollusc Buccinum undatum L., the periostracum, egg capsule and operculum. Comp Biochem Physiol 40B:37-46

Jokiel PL (1980) Solar ultraviolet radiation and coral reef epifauna. Science 207:1069-1071

Karentz D (1994) Ultraviolet tolerance mechanisms in Antarctic marine organisms. Antarct Res Ser 62:93-110

Karentz D, Bosch I, Dunlap WC (1992) Distribution of UV. absorbing compounds in the Antarctic limpet, Nacella concinna. Antarct J US 27:121-122

Karentz D, McEuen FS, Land MC, Dunlap WC (1991) Survey of mycosporine-like amino acid compounds in Antarctic marine organisms: potential protection from ultraviolet exposure. Mar Biol 108:157-166

Kerr JB, McElroy CT (1993) Evidence for large upward trends of ultraviolet-B radiation linked to ozone depletion. Science 262:1032-1034

LeBoeuf R (1971) Thais emarginata (Deshayes): description of the veliger and egg capsule. Veliger 14:205-211

Lord A (1986) Are the contents of egg capsules of the marine gastropod Nucella lapillus (L.) axenic? Am Malac Bull 4:201-203

Menge BA (1978) Predation intensity in a rocky intertidal community. Relation between predator foraging activity and environmental harshness. Oecologia 34:1-16

Palmer AR (1980) A comparative and experimental study of feeding and growth in thaidid gastropods. PhD dissertation, Univ of Washington, Seattle

Palmer AR (1994) Temperature sensitivity, rate of development, and time to maturity: geographic variation in laboratory-reared Nucella and a cross-phyletic overview. In Wilson WH Jr, Stricker SA, Shinn GL (eds) Reproduction and development of marine invertebrates. John Hopkins University Press, Baltimore, p 177-194

Palmer AR, Gayron SD, Woodruff DS (1990) Reproductive, morphological, and genetic evidence for two cryptic species of northeastern Pacific Nucella. Veliger 33 : $325-338$

Pechenik JA (1978) Adaptations to intertidal development: studies on Nassarius obsoletus. Biol Bull 154:282-291

Pechenik JA (1982) Ability of some gastropod egg capsules to protect against low-salinity stress. J Exp Mar Biol Ecol 63 : $195-208$

Pechenik JA (1983) Egg capsules of Nucella lapillus (L.) protect against low-salinity stress. J Exp Mar Biol Ecol 71:165-179
Pechenik JA (1986) The encapsulation of eggs and embryos by molluscs: an overview. Am Malac Bull 4:165-172

Pennington JT, Emlet RB (1986) Ontogenetic and diel vertical migration of a planktonic echinoid larva, Dendraster excentricus (Eschscholtz): occurrence, causes, and probable consequences. J Exp Mar Biol Ecol 104:69-95

Price NR, Hunt S (1973) Studies of the cross-linking regions of whelk egg-capsule proteins. Biochem Soc Trans 1. $158-159$

Price NR, Hunt S (1974) Fluorescent chromophore components from the egg capsules of the gastropod mollusc Buccinum undatum (L.), and their relation to fluorescent compounds in other structural proteins. Comp Biochem Physiol 47B:601-616

Price NR, Hunt S (1976) An unusual type of secretory cell in the ventral pedal gland of the gastropod mollusc Buccinum undatum L. Tiss Cell 8:217-228

Rawlings TA (1990) Associations between egg capsule morphology and predation among populations of the marine gastropod, Nucella emarginata. Biol Bull 179: $312-325$

Rawlings TA (1994) Encapsulation of eggs by marine gastropods. effect of variation in capsule form on the vulnerability of embryos to predation. Evolution 48:1301-1313

Rawlings TA (1995a) Encapsulation of eggs by the rocky shore marine gastropod Nucella emarginata: costs and benefits of variation in capsule form. PhD dissertation Univ of Alberta, Edmonton

Rawlings TA (1995b) Direct observation of encapsulated development in muricid gastropods. Veliger 38:54-60

Robberecht R, Caldwell MM, Billings WD (1980) Leaf ultraviolet optical properties along a latitudinal gradient in the arctic-alpine life zone. Ecology 61:612-619

Shick JM, Dunlap WC, Chalker BE, Banaszak AT, Rosenzweig TK (1992) Survey of ultraviolet radiation-absorbing mycosporine-like amino acids in organs of coral reef holothuroids. Mar Ecol Prog Ser 90:139-148

Smith RC, Prézelin BB, Baker KS, Bidigare RR, Boucher NP, Coley TC, Karentz D, MacIntyre S, Matlick HA, Menzies D. Ondrusek M, Wan Z, Waters KJ (1992) Ozone depletion: ultraviolet radiation and phytoplankton biology in Antarctic waters. Science 255:952-959

Sokal RR, Rohlf FJ (1981) Biometry, 2nd edn. W. H. Freeman and Company, New York

Spight TM (1974) Sizes of populations of a marine snail. Ecology $55: 712-729$

Spight TM (1977) Do intertidal snails spawn in the right places? Evolution 31:682-691

Stochaj WR, Dunlap WC, Shick JM (1994) Two new UVabsorbing mycosporine-like amino acids from the sea anemone Anthopleura elegantissima and the effects of zooxanthellae and spectral irradiance on chemical composition and content. Mar Biol 118:149-156

Strathmann MF (1987) Reproduction and development of marine invertebrates of the northern Pacific coast. Univ of Washington Press, Seattle

Sullivan CH, Maugel TK (1984) Formation, organization, and composition of the egg capsule of the marine gastropod, llyanassa obsoleta. Biol Bull 167:378-389

Thorson G (1950) Reproductive and larval ecology of marine bottom invertebrates. Biol Rev 25:1-45

Thorson G (1964) Light as an ecological factor in the dispersal and settlement of larvae of marine bottom invertebrates. Ophelia 1:167-208

Vogelmann TC, Bjorn LO (1984) Measurements of light gradients and spectral regime in plant tissue with a fiber optic probe. Physiol Plant 60:361-368 
Vogelmann TC, Knapp AK, MCClean TM, Smith WK (1988) Measurement of light within thin plant tissues with fiber optic microprobes. Physiol Plant 72:623-630

Vogelmann TC, Martin G, Chen G, Buttry G (1991) Fiber optic microprobes and measurement of the light micro-

This article was presented by J. M. Shick (Senior Editorial Advisor), Orono, Maine, USA environment within plant tissues. Adv Bot Res 18:231-270 Worrest RC (1982) Review of literature concerning the impact of UV-B radiation upon marine organisms. In: Calkins $J$ (ed.) The role of solar ultraviolet radiation in marine ecosystems. Plenum Press, New York, p 429-457

Manuscript first received: July 13, 1995

Revised version accepted: November 16, 1995 